\title{
Electronic Record
}

National Cancer Institute

\section{Source}

National Cancer Institute. Electronic Record. NCI Thesaurus. Code C142531.

A collection of digital data that is managed and processed by a computer system. 